\title{
Don't Mind the Gap: Intuitions, Emotions, and Reasons in the Enhancement Debate
}

$\mathrm{O}$ ur moral judgments about bioethical issues (as about many other issues) tend to be heavily affected by our intuitive and emotional responses. This is not surprising if we think of how often bioethical issues touch on our taboos and deeply held values. Consider the recent debate on so-called after-birth abortion, for example. According to a prominent conservative thinker, "anyone should immediately be able to see that killing infants because they are unwanted is unacceptable" (emphasis added). ${ }^{1}$ The word "immediately" here suggests that it is our intuition, before any possible argument, that tells us that infanticide is impermissible. This is just one example of a common approach to (at least some) bioethical issues. Reliance on intuitive and emotive responses is widespread across many other areas of bioethics. The current debate on biotechnological human enhancement is particularly interesting in this respect. A strand of "bioconservatives" that has explicitly drawn connections to the modern conservative tradition, dating back to Edmund Burke, ${ }^{2}$ appeals to the alleged wisdom of our intuitions and emotions to ground opposition

Alberto Giubilini, "Don't Mind the Gap: Intuitions, Emotions, and Reasons in the Enhancement Debate," Hastings Center Report 45 (2015): 1-9. DOI: 10.1002/hast. 458 to some biotechnologies or their uses. Such reliance on intuitions and emotions is widely acknowledged as one of the distinguishing features of this conservative strand by both its supporters ${ }^{3}$ and opponents. ${ }^{4}$ Granted, a number of antienhancement positions exist that clearly do not fall within the conservative tradition of social and political thought ${ }^{5}$ - for example, positions that raise objections based on egalitarian arguments. ${ }^{6}$ What distinguishes the conservative strand examined here is, however, its focus on the methodology of bioethical discussion and particularly on the weight that intuitions and emotions should play in such discussion.

Two argumentative strategies have been adopted to philosophically defend the role of intuitions and emotions in bioethical debates. The first strategy is to claim that at least some intuitive and emotive responses - particularly about "playing God" with human nature-capture something beyond our reasoning capacity that nonetheless expresses some form of not fully articulable "wisdom," such as particular insights about human dignity. ${ }^{8}$ Michael Sandel has suggested that our capacity to grasp the wrongness of playing God with genetics is limited by the too-narrow language of modern ethics, which is based only on the three notions of "autonomy, fairness, and individual rights." Leon Kass offered 
perhaps the most famous formulation of this intuitive and emotive bioconservative approach when he wrote that "[i]n crucial cases . . . repugnance is the emotional expression of deep wisdom, beyond reason's power to fully articulate it .... To pollution and perversion, the fitting response can only be horror and revulsion; and conversely, generalized horror and revulsion are prima facie evidence of foulness and violation." 10

The second-and more conciliatory-strategy is to appeal to a form of what might be dubbed "companions-in-guilt arguments." ${ }^{11}$ The idea here is that no moral approach is ultimately based solely on reasons, and therefore the explicit appeal to intuitions and emotions is no more flawed than arguments displaying logic and reasons. ${ }^{12} \mathrm{~A}$ neo-Humean version (one adapted from the philosophy of David Hume) of this view holds that there is room for reasons and arguments in (bio)ethics, but only as long as they concern empirically verifiable facts and comparisons between relevantly similar cases or generalizations from cases, but not when discussing moral principles themselves. ${ }^{13}$ Moral evaluations are the result of the projection onto a state of affairs of human attitudes and concerns, ${ }^{14}$ which also affect our perception of the wrongness of altering (human) nature through bioenhancement. ${ }^{15}$

So-called bioliberals, those who in principle do not oppose human bioenhancement, tend to rely on rational arguments and to see intuitions and emotions mostly as sources of biases. This approach often translates into shifting the burden of proof onto bioconservatives and challenging them to provide arguments against the proposed enhancement to back what bioliberals perceive as merely intuitive, emotive, and irrational reactions. ${ }^{16}$

In this article, I am going to show that the methodological divide between bioliberals and bioconservatives is less significant than at first glance it appears to be and less significant than it is often taken to be. I will do so by defending two theses. The first is that reliance on intuitions and emotions is not a prerogative of bioconservatives: bioliberals have their typical intuitions and emotive responses and are for this reason exposed to potential biases in the same way as bioconservatives are. The second thesis is that reliance on intuitions and emotions is not necessarily antithetic to reason and rationality. This latter thesis has been philosophically defended with particular reference to the debate on biotechnologies, ${ }^{17}$ while the former is perhaps more controversial and more difficult to accept —at least for bioliberals. In both cases, I will support the claims by drawing on resources from the field of moral psychology and the sciences of the mind and, particularly, by applying to some positions in the enhancement debate recent findings about the role of intuitions and emotions in human moral assessment. This new empirically informed perspective holds promises for solving the methodological controversy between bioconservatives and bioliberals. My aim is not, of course, to find a common ground on substantial ethical issues concerning the permissibility of cloning or of enhancement. ${ }^{18}$ Nor is my aim that of going beyond a polarization on substantial issues between liberals and conservatives that after all characterizes many forms of disagreements (religious, political, moral). However, it is essential to find some common methodological premise starting from which a proper dialogue and a proper debate might take place. Sharing a methodology for ethical discussion is important because, as I will show, dismissing bioethical positions merely on the basis of their methodological assumptions-as participants in the debate on biotechnology often do-can lead authors to overlook important insights coming from the opposite field.

The view that intuitions, emotions, and rationality are not mutually exclusive but actually interdependent has a long philosophical tradition. It dates back at least to
Aristotle's conception of the virtuous man as someone capable of intuitive insights, up to contemporary debates about the (alleged) wisdom of experts' intuitions ${ }^{19}$ and neo-Humean interpretations of moral reasoning in the debate on biotechnologies. ${ }^{20}$ The same view is supported by recent findings and theories in neurobiology and moral psychology and subsequent developments in metaethics. ${ }^{21}$ Consider, for example, findings and theories about the essential role of emotions for the correct functioning of our practical rationality 22 and of intuitions in our moral and practical decision-making. ${ }^{23}$ These theories have informed critical analysis that is relevant to many areas of applied philosophy_from risk-assessment ${ }^{24}$ to interpretation of political divisions. ${ }^{25}$ Quite surprisingly, in spite of the controversy regarding the (alleged) wisdom of intuitions and emotions in bioethics, the debate about enhancement biotechnologies has remained untouched by the potential insights that this kind of psychological reflection might bring. This paper aims to fill this gap in the literature.

A note on terminology is necessary. Following a common trend in moral psychology, ${ }^{26}$ metaethics, ${ }^{27}$ and applied ethics ${ }^{28}$ alike, I will consider, for the present purposes, "emotions" and "intuitions" as two relevantly similar types of mental phenomena and use the terms (almost) interchangeably. Both intuitions and emotions happen automatically and without awareness, and both can have cognitive contents and be motivational at the same time. According to Sabine Roeser, for example, "[E]thical intuitions are paradigmatically cognitive moral emotions," 29 and according to Jonathan Dancy, " $[R]$ ecent intuitionism can allow itself a richer conception of intuition, one that allows us to think of an intuition as intrinsically motivational, and so not 'purely' cognitive." ${ }^{30}$ Jonathan Haidt proposes that "cognitive elements of emotions - such as appraisals of events and alterations of attention and vigilance-are subtypes of intuitions" 
that "happen automatically and with conscious awareness of the outputs, but not of the process." ${ }^{31}$ Ultimately, this literature seems to concur with Dancy on the claim that "the standard contrast between intuition and emotion is a mistake." 32

\section{Intuitions, Emotions, and Biases in (Bio)ethics}

Tudgments, including ethical ones, $\int$ that are not based on rational scrutiny but instead grounded in emotions and intuitions are often subject to biases. ${ }^{33}$ I use "bias" in a very general sense to include all the distorting psychological (including emotional) mechanisms that systematically affect the rationality of a certain (moral or nonmoral) judgment. For instance, an "affect heuristics" 34 - a tendency to make quick judgments based on feelings rather than calculationmay bias risk assessment. Fear, for example, leads people to amplify risk estimates: the more dreadful a certain outcome is, the more probable it is perceived to be, and the same holds for a range of negative emotions. ${ }^{35}$ "Probability neglect" is another interesting psychological phenomenon whereby, when assessing a certain risk, people become the less sensitive to information about the actual probabilities of a certain outcome, the worse the feeling experienced about that outcome. ${ }^{36}$ Risk assessment is not a type of moral judgment, but it can affect moral judgments if, and to the extent that, moral judgments need to take consequences and probabilities into account.

Other kinds of distorting factors affect more directly moral intuitions, in other words, moral beliefs that are held "independent of any process of inferring them from any other belief." ${ }^{37}$ One such factor is the socalled framing effect, the tendency to assess a certain scenario depending on how it is described rather than on what it actually contains. For example, our intuitions about the moral permissibility of the different options in the well-known imagined trolley case are heavily affected by the way the options are described. A study has shown that people tend to consider the very same option-for instance, diverting the trolley to a side track so that one person instead of five will be killed-more permissible if it is described in terms of the persons who would be saved rather than in terms of the persons who would be killed. ${ }^{38}$

It is interesting to note, however, that, despite such unreliability, many thought experiments and theoretical frameworks that are used to ground substantial bioethical positions are based on moral intuitions or emotions. The trolley case, first introduced to discuss the morality of abortion, ${ }^{39}$ is just one example. In what is known as the "non-identity problem," Derek Parfit focused on the intuition that it is impermissible to conceive a child with a certain (mild) disease when a normal child could be easily conceived instead (for instance by postponing the intended pregnancy by a few months)..$^{40}$ The non-identity problem is a "problem" precisely because it is hard to justify rationally the intuition if we consider that the alternative for the potential mildly handicapped child would be nonexistence. The intuition in the non-identity problem is currently upheld to support "bioliberal" positions in the enhancement debate, such as the idea that we could or even should select the "best" embryo in the case of in vitro fertilization although failing to do so would not harm anyone. ${ }^{41}$ One might wonder whether reliance on intuitions in such cases is any different, with regard to the risk of biases, from reliance on intuitions by bioconservatives.

Recent studies and findings in moral psychology suggest that in the vast majority of cases, our moral judgments are the expression of intuitions or emotions, rather than of reason alone. ${ }^{42}$ According to the social intuitionist model proposed by Jonathan Haidt, reasoning and principles are, at best, post hoc rationalizations of our intuitive and emotive evaluations. This is illustrated by the many cases of "moral dumbfounding," when people unsuccessfully try to provide reasons that they think a certain practice-for instance, secret incest between consenting adults, with contraception used-is wrong, but still are not willing to give up their conviction after they are shown that what they say cannot do the explanatory work. For instance, one reason often provided in discussion about this kind of incest is that it would entail the risk of genetic abnormalities in the offspring, but subjects would not change their negative evaluation of incest even if it were pointed out that different contraceptives would be used; rather, they would come up with some alternative reason to explain their evaluation, but, again, this reason could be easily dismissed without any effect on their moral stance, and so on. This suggests that such a stance is grounded in a strong intuition rather than in reasons and, more importantly, that because of this intuitive or emotive nature, the stance is likely to be irrational or biased. ${ }^{43}$

Often these psychological findings have focused on the difference between the moral psychology of selfreported liberals and of self-reported conservatives. Interestingly, evidence suggests that reliance on intuitions and emotions is not a prerogative of the "conservative mind"; rather, the difference between liberals and conservatives is that they rely on different sets of intuitions. ${ }^{44}$ And the same seems to be true if, instead of intuitions, we consider the emotional aspects of the conservative and liberal approaches. Evidence suggests, for example, that the autonomy-based morality that defines the liberal approach is characterized by a specific emotion, namely anger, that is generally aroused when autonomy violations occur, as opposed to emotions such as contempt or disgust that characterize the conservative approach. ${ }^{45}$ Also in this case, the difference between liberals and conservatives is based on two different sets of emotions, rather than on the different use they make of arguments and reasoning. 
Intuitions, Emotions, and Biases in Bioconservatives

Tany philosophers are skepti1 cal about the role of intuitions and emotions in ethics. Skepticism is particularly pronounced in bioethics because scientific progress constantly proposes new possible scenarios that are very different from the ones that have shaped the evolutionary development of intuitions and emotions in the human mind. ${ }^{46}$ For instance, some bioliberals claim that opposition to human enhancement that is based on intuitions or emotions is easily subject to status quo bias and that it is subject to this type of bias precisely because it is based on intuitions and emotions rather than reason. ${ }^{47}$ Status quo bias is defined as an "inappropriate (irrational) preference for an option because it preserves the status quo" (p. 658). The key words here are "irrational" and "inappropriate." What makes a preference irrational and inappropriate? If we want to claim that a piece of reasoning is biased and irrational, we presumably need a standard of rationality to appeal to. The "Reversal Test" devised by Nick Bostrom and Toby Ord is a proposed standard. According to this, if an opponent of a certain form of enhancement (increasing the level of serotonin in our brain to improve impulse control, for instance ${ }^{48}$ ) is not willing to claim that a certain parameter in the human physiology should be modified in the opposite direction (decreasing the level of serotonin), and if the opponent cannot demonstrate that the current level of that parameter is optimal either, then, other things being equal (for example, there is no significant transition cost involved), the opposition to that enhancement intervention is biased. Concerns about interfering with the course of evolution, which are often put forward by bioconservatives, ${ }^{49}$ might be seen as an example of status quo bias.

The distorting influence of emotions on risk assessment ${ }^{50}$ provides a further reason for thinking that bioconservatives might be biased in their assessment of the possible consequences of the use of some biotechnologies. The mere possibility that some new biotechnologies such as genetic engineering or cloning would bring about scary scenarios like the ones depicted in fictional works such as Gattaca or Brave New World could make these scenarios look more probable than they actually are. There is evidence showing such mechanisms at work in perception of risk and acceptance of nuclear power. ${ }^{51}$ Prospects fueled by sci-fi novelists or the Hollywood industry might affect judgments on the permissibility of biotechnologies in the same way. It is noteworthy that some of the most strenuous opponents of enhancement biotechnologies often remind people of scary fictional scenarios or other things that cast a shadow over our "posthuman future" in order to support their positions. ${ }^{52}$ This might be a strategy to instill a sentiment of fear in others, but might also be a symptom of bioconservatives' own fears, which might distort their probabilistic assessment of the possible consequences of adopting certain biotechnologies.

\section{Intuitions, Emotions, and Biases in Bioliberals}

W hether Haidt's (and colleagues') theory about the intuitive and emotive foundations of the liberal mind is true is debatable on empirical grounds, and not all the evidence available supports the social intuitionist model. ${ }^{53}$ What is true is that bioliberals do base some of their arguments on unanalyzed intuitions, in spite of their defense of rationality in ethics. For example, it is only by accepting the intuitive response to the non-identity problem that John Harris and Julian Savulescu can endorse the principle of procreative beneficence: since no harm would be done to the future person if a "normal" or even a defective embryo were implanted instead of the "best embryo," it is hard to argue that there is a moral obligation to select the best embryo in order to give the best start in life to your child. Parfit admitted his frustration at not being able to provide the "Theory X" that justifies this kind of intuition; Harris and Savulescu just seem to take the intuition as a solid basis for their arguments. As Rebecca Bennett puts it, "Unlike [with] Parfit, Harris and Savulescu's examples are used to show that because we feel that a choice is wrong it therefore must be actually wrong to make these choices" (emphasis added). ${ }^{54}$

Or take again the Reversal Test, which arguably is a perfect example of bioliberals' "rational" approach. The test might offer a useful conceptual tool to certify the rationality of procreative beneficence. Bioliberals might argue that if you think that selecting the best embryo is not permissible, then the burden of proof is on you to demonstrate that either (1) the opposite solution would be better (choosing the "worst" embryo) or (2) the current state is optimal (the natural lottery is optimal); if you can't do that, then your position is affected by a status quo bias. No bioconservative would uphold 1 , and probably very few would bite the bullet by buying 2. However, this heuristics sets some rules of the game that might themselves be questioned. For example, enhancement implemented in the form of a "liberal eugenics" policy might actively promote inequalities in any given society between those who can and those who cannot (and maybe in some cases do not want to) undergo enhancement interventions; ${ }^{55}$ in other words, egalitarian goals might not be adequately promoted in a society where enhancements are liberally pursued, ${ }^{56}$ even if within a liberal framework enhancing were the most rational option according to the reversal test. So, in virtue of the questionability of these rules, an opponent of enhancement might consistently claim that neither 1 nor 2 is true, but that from this negation it does not follow that procreative beneficence is a valid principle. In other words, one might argue that 
the reversal test is an expression of a "neoliberal orthodoxy" 57 of individualistic choice in free markets, which is simply assumed but not critically assessed, for example, in light of the aforementioned egalitarian objections.

At this point, one might argue that it simply is not true that bioliberals rely on an uncritical and intuitive endorsement of liberty in spite of the potential costs in terms of equality. In fact, the bioliberal approach is often presented by its defenders as the result of a reasonable balance between liberal and egalitarian requirements. There are, however, reasons to be suspicious, if we analyze the different claims bioliberals have put forward to defend their views against equality-based objections. There are at least four such claims. The first is empirical in nature: some bioliberals have pointed out that bioenhancements would become progressively, and relatively rapidly, accessible to almost everyone, as has been the case with many other new technologies. ${ }^{58}$ The second claim is that bioenhancement could actually promote equality by correcting the unfairness of the genetic lottery, for instance, if we prioritized enhancements of those with a low level of functioning of any capacity. ${ }^{59}$ The third claim is that equality matters, but not so much as to outweigh the importance of liberty to make procreative choices. ${ }^{60}$ Finally, some have pointed out that we already accept, and indeed promote, inequalities through other, more traditional means (for instance, by allowing those who can afford to send their children to private schools to do so), and there is no reason for thinking that the same inequalities brought about through new forms of human enhancement should be considered morally different. ${ }^{61}$

Analyzing each of these claims would be well beyond the scope of this paper. What I want to point out here is that a liberal defense of enhancement cannot consistently embrace all of them to respond to equality-based objections, because some of these ar- gumentative strategies are mutually exclusive. For instance, either it is reasonable to predict, based on empirical evidence about the diffusion of other technologies, that enhancement will result in inequalities, or it is not. If it is not, then no further argument is required to address the objection. If it is, then either the value of liberty and of the expected utility that enhancement might bring about outweighs equality costs (at least when these costs are not too high), or it does not. If it does, then, again, no further argument is required. If it does not, then bioliberals are required to provide other arguments, for example the argument that enhancement actually promotes equality. The point is that in the presence of different possible and mutually exclusive strategies, when one would be sufficient, it is hard to see how any of these strategies can do any actual justificatory work in defending enhancement from equality-based objections. These different possible responses look very much like post-hoc rationalizations of the intuition that liberty should be the guiding principle when it comes to human enhancement, no matter what the possible costs in terms of equality. But if this last claim is defensible, then reasons must be provided to support the point (and perhaps the intuition) that liberty matters more than equality when the two principles conflict with one another.

\section{"Reasoned Intuitions"?}

$\mathrm{O}$ ne important source of criticism of the intuitive and emotive account of moral judgments stems from the view that emotions, intuitions, and rationality cannot be separated in the way Haidt and other moral psychologists presuppose. Rather, as has been claimed, ethical intuitions and emotions "can be the source and the result of ethical reflection and deliberation." ${ }^{12}$ It is interesting to note how Haidt and Roeser use neurobiologist Antonio Damasio's studies on how our practical rationality requires the correct functioning of emotions ${ }^{63}$ to further their own, opposite causes. Haidt uses Damasio's observations as evidence in support of his thesis that our morality is based on emotions rather than on rationality, ${ }^{64}$ whereas Roeser uses the same evidence to support the thesis that our morality is based on emotion and therefore on rationality ${ }^{65}$ This suggests, at the very least, that the notion of "rationality" is in need of clarification, particularly with regard to its relation to emotions and intuitions.

What I want to focus on here is the evidence that suggests that intuitive and immediate responses in general can be the result of automatized processes based on explicit and consciously held reasons, thus expressing a form of rationality. This would imply that although most of our moral judgments might be intuitive or emotional, this is not the whole story, and some intuitive and emotional responses might deserve more attention and scrutiny than currently granted. Let's see more in details.

Two sets of empirical data are particularly interesting for the present discussion: First, high-priority and consciously held goals can prevail over temptations, stereotypes, and immediate reactions through a "behavioral inhibition system" once people have been made aware of having acted contrary to these goals and experience a self-directed negative feeling (in particular, experiments have focused on racial stereotypes that conflict with consciously held egalitarian goals). ${ }^{66}$ Second, the way high-priority (moral) goals can prevail can itself be an emotional or intuitive response, ${ }^{67}$ which is consistent with empirical findings about the automatization of high-priority (moral and nonmoral) goals. ${ }^{68}$

From empirical studies on resistance to temptations, for example, Fishbach and colleagues have concluded that "with continuing attempts at self-control individuals may develop facilitative links between representations of momentarily activated temptations and the corresponding high-priority goals with which they 
may interfere. Because of the general pervasiveness of self-control strivings, such facilitative links may be overlearned to the point of their a) subliminal activation, and $\mathrm{b}$ ) relative independence of cognitive resources." ${ }^{69}$ This means that people's automatic, immediate reactions might be due to higher-priority moral goals that are not directly recalled, but that have been overlearned so that their application does not require any conscious resource.

These results were replicated across a wide variety of (moral and nonmoral) goals, ${ }^{70}$ also outside the domain of temptations. John Bargh and colleagues, for instance, have detected such mechanisms at work when the goal activated is to perform well at tasks or to cooperate with others. These results have been interpreted as suggesting that "mental representations of goals can become activated without an act of conscious will, such that subsequent behavior is then guided by these goals within the situational context faced by the individual." ${ }^{\prime 1}$ In other words, "over time the goal representation will develop an automatic association with the features of those situations in which that goal has been repeatedly and consistently chosen and pursued in the past" (p. 1015) so that eventually environmental cues, rather than conscious choice, activate the (moral) goal.

The more general principle of psychology here at work is that, when the same goal is repeatedly activated in the same kind of situations, effortful conscious reflection tends to drop out, as no longer necessary to apply that goal, with the consequent judgments becoming automatized responses. ${ }^{72}$ More importantly for the present discussion, "on the basis of the assumption that goals become automated through their repeated selection in a given situation, such automatic goals should generally be in line with the individual's valued, aspired-to life goals and purposes." ${ }^{33}$ Actually, this evidence seems to provide empirical confirmation for the intuitionist claim that "intuitions are a product of our rational faculty," which "might be the result of a long process of reflection." 74

Let us now turn again to the enhancement debate to try to apply these insights. The fact that someone feels "repugnance" at the thought of human cloning or intuits the existence of a "Factor X" that accounts for human dignity ${ }^{75}$ means only that the individual's judgments on the impermissibility of using certain biotechnologies are not inferred from any principle. It does not mean, however, that the judgments cannot be justified by any principle (or "higher-priority moral goal") or that they are not explained by an independent reflection on moral goals that the individual has previously made, for example, due to his or her education or upbringing (for instance a reflection on the threat to egalitarian goals posed by a "neoliberal orthodoxy"). In the same way, an intuition that it is wrong to alter the course of evolution or God's plan is an immediate response that can arise on the background view that "playing God" is, for some reason, wrong, a view on which there is a philosophical debate where reasons can be given and assessed. And this is a view that, exactly like a "liberal orthodoxy" or an egalitarian objection, can be articulated and is subject to rational scrutiny.

\section{Rationality, Wisdom, and the Arena for the Enhancement Debate}

The lack of clarity surrounding the concept of "rationality" recommends caution when bestowing certificates of rationality to oneself, or of lack thereof to one's opponents, as bioliberals tend to do. The same is true when the concept invoked is that of "wisdom," which is more common among conservatives. Clearly defining "wisdom" is problematic because, as has been pointed out, "[t]here are as many definitions of wisdom as authors who attempt to understand what wisdom is." 76 Philosophical ac- counts of "wisdom" are often grounded in epistemic humility (the sense in which, for instance, Socrates was wise) or accuracy. Alternatively, they are based on knowledge about how to live well and on appreciation of the value of living well (in the sense of Aristotelian practical wisdom). ${ }^{77}$ Sometimes accounts are hybrid versions, including aspects of these different definitions. ${ }^{78}$ None of these definitions seem, however, to capture the meaning that Kass and other conservatives attach to the notion of wisdom. Their "wisdom" could rather be intended as a capacity for moral insights that make up for the limitations of our moral reasoning. As Levin writes, "[T]hese sentiments and insights are reasonable but not fully rational. They are wise but not fully explicit." ${ }^{\prime 79}$ In this view, intuitions and emotions are a source of wisdom, but wisdom is not the same as rationality. Nor is it something less or more than rationality. Simply, it is taken to be something different, but more powerful than rationality in providing moral insights. Why this should be the case is, however, unclear, considering that the best (in other words, empirically informed) explanation for why some intuitions and emotions can convey moral insights is that they are the result of automatized moral reflection. Rationality is not something easily separable from intuitions and emotions, but there is no need to postulate a separate faculty or virtue, such as "wisdom," to account for the fact that there might be deep insights speaking through our emotions or intuitions: reflection and reasons can and should be used to justify such insights.

To be sure, this analysis raises the complex philosophical problem of the foundation of morality, something whose discussion (let alone solution) is well beyond the scope of this paper. One might argue, in other words, that even this "second-order" rational defense would be grounded in some other intuition or emotion, thus triggering an infinite regress. Here I want just to point out that, 
even if infinite regress justified an intuitionist or a sentimentalist metaethics, we would still gain something in terms of reflective capacity and dialogue if we tried to dig a bit deeper than the first level of intuitive and emotive responses and to accept the idea that intuitions and emotions can express reasons, and sometimes good ones. My analysis aims at encouraging those who take part in bioethical discussion to work in both these directions, rather than dismiss opponent positions just because they are articulated through the (allegedly) narrow language of "autonomy, fairness and individual rights" 80 or because they are the product of intuitive or emotive reactions. ${ }^{81}$ As Kaebnick has put it, even if "[w]e will not be able to support our positions with arguments that are entirely noncircular, ... we should still be able to articulate, convey, and defend our views." 82 After all, even logic has fundamental principles that cannot be defended in terms of something other (or more fundamental) than logic itself, but this fact provides no reason to dismiss logic or to see logic as something precarious.

In light of the analysis conducted here, two things are required of participants in the enhancement debate. The first is the capacity to recognize the intuitions that ground one's moral stances, a task in which bioconservatives are certainly performing much better than bioliberals. The second is a convincing demonstration-a rational argument to the effect thatthe more general goals that these intuitions and emotions express are justifiable through arguments and reason-giving. If this justification through articulable reasons can be provided, then it would make sense to say that the intuitions or emotions through which they express themselves are a source of wisdom or, to use an equivalent word, of rationality.

The aim of this paper is to encourage both parties engaged in the enhancement debate to abandon what often looks like a methodological dogmatism (either against or in favor of intuitions and emotions). However, it is bioliberals, in other words, those more fiercely opposed to intuitions and emotions in ethical discussion, who have the most compelling reasons for overcoming their tendency to dismiss opponents' methodological approach. In fact, my analysis suggests that often their opponents' methodological approachreliance on intuitive and emotive stances-is also their own methodological approach.

Furthermore, bioliberals are called on to make a bigger effort than bioconservatives to overcome their skepticism toward their opponents' methodological approach. One important aspect of bioethical discussion that is often overlooked is that bioconservatives are frequently keen to provide reasons and arguments in support of their intuitions. ${ }^{83}$ Even Kass, after having claimed that repugnance might be the last voice that speaks up in defense of our humanity, outlines some more general concerns about cloning and the wide use of biotechnologies in human reproduction that go beyond mere reliance on gut feelings, for instance, slippery slope arguments or concerns about confounding the moral relations and roles in a family. ${ }^{84}$ These concerns can be articulated and then assessed based on reason-giving, arguments, and reflection.

Bioconservatives should, however, be more open and explicit about this latter aspect of their argumentative strategy. There is no need to pushas they often do-the problematic thesis that intuitions and emotions are better than explicit arguments to put up a convincing case against enhancement. Consider the following example. Robert Sparrow has argued that moral bioenhancement threatens egalitarian goals because it foreshadows a division of classes where the morally enhanced, as in Plato's ideal republic (or perhaps as in Gattaca), would have a stronger claim to govern over, and therefore dominate, the morally "normal." 85 Now, it is not obvious that this would be a mor- ally impermissible outcome. Perhaps a platonic type of republic would be better than a democracy, all things considered. But this kind of issue demonstrates the importance of making reasons and underlying concerns explicit so that the ultimate moral or philosophical issues at stake-in this case, the right balance between egalitarian and liberal values-can be detected, unpacked, and rationally discussed, instead of remaining hidden and unexamined in intuitive and emotive responses that might or might not be wise.

\section{Acknowledgments}

I would like to thank Steve Clarke for very helpful comments on previous versions of this paper, as well as the editor and an anonymous reviewer of the Hastings Center Report for their suggestions on how to improve it. I also received extremely helpful feedback from audiences at the New Zealand Bioethics Conference, at the University of Otago, Dunedin, in January 2014, and during my presentations at the Center for Applied Philosophy and at the Public Ethics Seminar, on the Canberra and Wagga Wagga campuses, respectively, of Charles Sturt University. This research was supported under the Australian Research Council's Discovery Projects funding scheme (project number DP130103658).

\section{Notes}

1. R. George, "Infanticide and Madness," Journal of Medical Ethics 3, no. 5 (2013): 299-301, at 299.

2. Y. Levin, "The Paradox of Conservative Bioethics," The New Atlantis, no. 1 (2003): 53-65.

3. Levin, "The Paradox of Conservative Bioethics"; E. Cohen, "Conservative Bioethics and the Search for Wisdom," Hastings Center Report 36, no. 1 (2006): 44-56.

4. R. Macklin, "The New Conservatives in Bioethics: Who Are They and What Do They Seek?," Hastings Center Report 36, no. 1 (2006): 34-43; A. Charo, "Passing On The Right: Conservative Bioethics Is Closer Than It Appears," Journal of Law, Medicine and Ethics, 32 (2004): 307-14.

5. A. Giubilini and S. Sanyal, "The Ethics of Human Enhancement," Philosophy Compass 10, no. 4 (2015): 233-43. 
6. R. Sparrow, "Better Living through Chemistry? A Reply to Savulescu and Persson on 'Moral Enhancement,"' Journal of Applied Philosophy, 31 no. 1 (2014): 23-32; M. Mehlman and J. Botkin, Access to the Genome: The Challenge to Equality (Washington, D.C.: Georgetown University Press, 1998).

7. L. Kass, "The Wisdom of Repugnance: Why We Should Ban the Cloning of Humans," The New Republic, June 2, 1997, 17-26.

8. F. Fukuyama, Our Posthuman Future: Consequences of the Biotechnology Revolution (New York: Farrar, Straus and Giroux, 2002).

9. M. Sandel, "The Case against Perfection," The Atlantic, 293, no. 3 (2004): 51-62, at 51.

10. L. Kass, "The Wisdom of Repugnance," at 21.

11. H. Lillehammer, Companions in Guilt: Arguments for Ethical Objectivity (London: Palgrave MacMillan, 2007).

12. M. Hauskeller, "Reflections from a Troubled Stream: Giubilini and Minerva on After-Birth Abortion," Hastings Center Report, 42, no. 4 (2012): 17-20, at 18.

13. G. E. Kaebnick, "Reasons of the Heart: Emotion, Rationality, and the 'Wisdom of Repugnance,'” Hastings Center Report, 38 no. 4 (2008): 36-45.

14. S. Blackburn, Ruling Passions (New York: Oxford University Press, 1998).

15. G. E. Kaebnick, Humans in Nature: The World As We Find It and the World As We Create It (New York: Oxford University Press, 2014); see, especially, chapter 2.

16. J. Harris, Clones, Genes, and Immortality (New York: Oxford University Press), at 56-59 and 181; N. Agar, Liberal Eugenics: In Defence of Human Enhancement (Oxford: Blackwell, 2004), at 153; N. Bostrom and T. Ord, "The Reversal Test: Eliminating Status Quo Bias in Applied Ethics," Ethics 116, no. 4 (2006): 656-79; R. Macklin, "The New Conservatives in Bioethics."

17. Kaebnick, Humans in Nature.

18. It has been argued, however, that, in fact, even on some substantial issues such as the ideal of human "authenticity," the divide between "critics" and "enthusiasts" of human enhancement is not as marked as one might initially think. See E. Parens, Shaping Our Selves: On Technology, Flourishing, and a Habit of Thinking (New York: Oxford University Press, 2015); see, especially, chapter 3.

19. L. Bortolotti, "Does Reflection Lead to Wise Choices?," Philosophical Explorations 14, no. 3 (2011): 297-313; J. Weinberg et al., "Are Philosophers Expert Intuiters?," Philosophical Psychology 23, no. 3 (2010): 331-55.

20. Kaebnick, Humans in Nature.
21. See, for example, S. Roeser, Moral Emotions and Intuitions (Basingstoke, UK: Palgrave Macmillan, 2010).

22. See, for example, A. Damasio, Descartes' Error: Emotion, Reason, and the Human Brain (New York: Putnam, 1994).

23. See, for example, T. Gilovich, D. Griffin, D. Kahneman, eds., Heuristics and Biases: The Psychology of Intuitive Judgement (New York: Cambridge University Press, 2002); J. Haidt, The Righteous Mind: Why Good People Are Divided by Politics and Religion (New York: Pantheon, 2002).

24. D. Kahneman, Thinking, Fast and Slow (Farrar, Straus and Giroux, 2011); Gilovich et al., Heuristics and Biases; S. Roeser, "Intuitions, Emotions and Gut Reactions in Decisions about Risks: Towards a Different Interpretation of 'Neuroethics,'" Journal of Risk Research 13, no. 2 (2010): 175-90.

25. J. Graham, J. Haidt, and B. Nosek, "Liberals and Conservatives Use Different Sets of Moral Foundations," Journal of Personality and Social Psychology 96 (2009): 1029-46; Haidt, The Righteous Mind.

26. See, for example, Haidt, The Righteous Mind, at 45, and Roeser, "Intuitions,

Emotions and Gut Reactions in Decisions about Risks."

27. See, for example, J. Dancy, "Intuition and Emotion," Ethics 124, no. 4 (2014): 787-812.

28. See, for example, R. Bennett, "When Intuition Is Not Enough: Why the Principle of Procreative Beneficence Must Work Much Harder to Justify Its Eugenic Vision," Bioethics, 28, no 9: 447-55.

29. Roeser, "Intuitions, Emotions and Gut Reactions in Decisions about Risks," 180.

30. Dancy, "Intuition and Emotion," 790.

31. Haidt, The Righteous Mind, 329.

32. Dancy, "Intuition and Emotion," 788.

33. Kahneman, Thinking, Fast and Slow; D. Kahneman D. and A. Tversky, "Choices, Values, and Frames," American Psychologist 39, no. 4 (1984): 341-50; A. Tversky and D. Kahneman, "Judgment under Uncertainty: Heuristics and Biases," Science, 185 (1974): 1124-31.

34. M. Finucane et al., "The Affect Heuristic in Judgments of Risks and Benefits," Journal of Behavioral Decision Making 13 (2000): 1-17; P. Slovic et al., "The Affect Heuristic," in Heuristics and Biases, ed. Gilovich et al., 397-420.

35. P. Slovic and E. Peters, "Risk Perception and Affect," Current Directions in Psychological Science 15, no. 6 (2006): 322-25; J. Lerner et al., "Effects of Fear and Anger on Perceived Risks of Terrorism: A National Field Experiment," Psychological Science 14, no. 2 (2003): 144-50.
36. C. Sustein, "Terrorism and Probability Neglect," Journal of Risk and Uncertainty 26, no. 2 (2003): 121-36, at 133.

37. W. Sinnott-Armstrong, "Framing Moral Intuitions," in The Neuroscience of Morality: Emotions, Brain Disorders, and Development, ed. W. Sinnott-Armstrong, (Cambridge, MA: MIT Press, 2008), $47-$ 82 , at 47.

38. L. Petrinovich and P. O'Neill, "Influence of Wording and Framing Effects on Moral Intuitions," Ethology and Sociobiology 17 (1996): 145-71.

39. P. Foot, "The Problem of Abortion and the Doctrine of Double Effect," Oxford Review 5 (1967): 5-15.

40. D. Parfit, Reasons and Persons (Oxford: Claredon Press, 1987), at 367-68.

41. J. Savulescu, "Procreative Beneficence: Why We Should Select the Best Children," Bioethics, 15, no. 5/6 (2001): 413-26; see also Bennett, "When Intuition Is Not Enough."

42. Haidt, The Righteous Mind; J. Greene, "The Secret Joke of Kant's Soul," in The Neuroscience of Morality: Emotions, Brain Disorders, and Development, ed. Sinnott-Armstrong, 35-79.

43. Haidt, The Righteous Mind, 74-92.

44. Ibid.

45. Rozin et al., "The CAD Triad Hypothesis: A Mapping between Three Moral Emotions (Contempt, Anger, Disgust) and Three Moral Codes (Community, Autonomy, Divinity)," Journal of Personality and Social Psychology 76, no. 4 (1999): 574-86.

46. R. Roache and S. Clarke, "Bioconservatism, Bioliberalism, and the Wisdom of Reflecting on Repugnance," Monash Bioethics Review 28, no. 1 (2009): $1-21$.

47. Bostrom and Ord, "The Reversal Test," 669.

48. G. Kahane and J. Savulescu. "Normal Human Variation: Refocusing the Enhancement Debate," Bioethics (early epub August 2, 2013): doi:10.1111/ bioe. 12045

49. Fukuyama, Our Posthuman Future, 7.

50. Slovic and Peters, "Risk Perception and Affect"; Sustein, "Terrorism and Probability Neglect."

51. E. Peters and P. Slovic, "The Role of Affect and Worldviews as Orientating Dispositions in the Perception and Acceptance of Nuclear Power," Journal of Applied Social Psychology 26, no. 16 (1996): 1427-53.

52. L. Kass, Toward a More Natural Science: Biology and Human Affairs (New York: Free Press, 1985), 35; Fukuyama, Our Posthuman Future, 5-6; Sandel, "The Case against Perfection," 54; R. Sparrow, "A NotSo-New Eugenics: Harris and Savulescu on 
Human Enhancement," Hastings Center Report 41, no. 1 (2011): 32-42, at 34.

53. J. Kennett and C Fine, "Will the Real Moral Judgment Please Stand Up? The Implications of Social Intuitionist Model for Meta-ethics and Moral Psychology," Ethical Theory and Moral Practice 12, no. 1 (2009): 77-96; C. Fine, "Is the Emotional Dog Wagging its Rational Tail, or Chasing It?," Philosophical Explorations 9, no. 1 (2006): 83-98.

54. Bennett, "When Intuition Is Not Enough," at 4.

55. See, for example, Sparrow, "A NotSo-New Eugenics"; Sparrow, "Better Living through Chemistry?"

56. M. Selgelid, "Moderate Eugenics and Human Enhancement," Medicine, Health Care and Philosophy 17 no. 1 (2014): 3-12.

57. K. Birch, "Neoliberalising Bioethics: Bias, Enhancement and Economistic Ethics," Genomics, Society and Policy 4, no. 2 (2008): 1-10.

58. A. Sandberg and J. Savulescu, "The Social and Economic Impacts of Cognitive Enhancement," in Enhancing Human Capacities, ed. J. Savulescu, R. Ter Meulen, and G. Kahane (Oxford: Wiley-Blackwell, 2011), 92-113.

59. A. Buchanan et al., From Chance to Choice: Genetics and Justice (Cambridge: Cambridge University Press 2000); J. Savulescu, "Justice, Fairness, and Enhancement," Annals of the New York Academy of Sciences 1093 (2006): 321-38.

60. J. Savulescu, "In Defence of Procreative Beneficence: A Reply to Parker," Journal of Medical Ethics 33, no. 5 (2007): 284-88, at 288; Savulescu, "Procreative Beneficence," 423.
61. S. Chan and J. Harris, "In Support of Human Enhancement," Studies in Ethics, Law, and Technology 1, no. 1 (2007): article 10 .

62. Roeser, "Intuitions, Emotions and Gut Reactions in Decisions about Risks," 175.

63. Damasio, Descartes' Error. 64. Haidt, The Righteous Mind, 65.

65. Roeser, "Intuitions, Emotions and Gut Reactions in Decisions about Risks," 180.

66. M. Monteith, "Self-Regulation of Prejudiced Responses," Journal of Personality and Social Psychology 65, no. 3 (1993): 46985; M. Monteith, et al., "Putting the Brakes on Prejudice: On the Development and Operation of Cues for Control," Journal of Personality and Social Psychology 83, no. 5 (2002): 1029-50.

67. Roeser, "Intuitions, Emotions and Gut Reactions in Decisions about Risks."

68. A. Fishbach, R. Friedman, A. Kruglanski, "Leading Us Not unto Temptation: Momentary Allurements Elicit Overriding Goal Activation," Journal of Personality and Social Psychology 84, no. 2 (2003): 296-309; J. Bargh et al., "The Automated Will: Nonconscious Activation and Pursuit of Behavioral Goals," Journal of Personality and Social Psychology 81, no. 6 (2001): 1014-27; J. Bargh and T. Chartrand, "The Unbearable Automaticity of Being," American Psychologist 54, no. 7 (1999): 462-79.

69. Fishbach et al., "Leading Us Not unto Temptation: Momentary Allurements Elicit Overriding Goal Activation,” 298.

70. Ibid.; see p. 306.
71. Bargh et al., "The Automated Will," 1015.

72. Bargh et al., "The Unbearable Automaticity of Being," 468-69 and 47374.

73. Bargh et al., "The Automated Will," 1016.

74. Roeser, "Intuitions, Emotions and Gut Reactions in Decisions about Risks," 180; Bortolotti, "Does Reflection Lead to Wise Choices?," 306.

75. Fukuyama, Our Posthuman Future.

76. Bortolotti, "Does Reflection Lead to Wise Choices?," 300.

77. R. Nozick, "What Is Wisdom and Why Do Philosophers Love It So?," in The Examined Life: Philosophical Meditations, by R. Nozick (New York: Simon and Schuster, 1989): 267-78, at 269; S. Ryan, "What Is Wisdom?," Philosophical Studies 93, no. 2 (1999): 119-39.

78. S. Ryan, "Wisdom," The Stanford Encyclopedia of Philosophy, ed. Edward N. Zalta, 2013, http://plato.stanford.edu/archives/sum2013/entries/wisdom/.

79. Levin, "The Paradox of Conservative Bioethics," 55.

80. Sandel, "The Case against Perfection," 51.

81. For a development of this point, see the interesting discussion in Parens, Shaping Our Selves, particularly p. 46.

82. Kaebnick, Humans in Nature, 43.

83. Levin, "The Paradox of Conservative Bioethics."

84. Kass, "The Wisdom of Repugnance," 21.

85. Sparrow, "Better Living through Chemistry?" 